\title{
The 2011 Waseda University World e-Government Ranking
}

The Waseda University Institute of e-Government has released the 2011 Waseda University World eGovernment Ranking, marking its seventh consecutive year of monitoring the development of e-Government worldwide. Prof. Dr. Toshio Obi, Director of the Institute and Head of the research team submitted this report. Professor Obi observed that ICT can be a powerful tool to current economic issues and in doing so, consolidate an inclusive Information Society. Governments are key actors in this process in building towards a citizen-oriented state.

\section{Singapore and USA keep competitive dead heat for the top ranking, followed by Sweden}

Just a slight advantage allowed Singapore to remain atop the Ranking for the third year in a row, followed by USA which had been placed first during 2005-2008 and second in 2010. Achieving breakthrough performance Sweden was ranked third, followed by Korea and Finland. Estonia having significantly improved its e-government development scores entered top 8 and Belgium became the top 9 for the first time in 2011 survey. The complete list of the top 15 countries (economies) which have the most advanced development in e-government according to the Waseda Survey are: (1) Singapore, (2) USA, (3) Sweden, (4) Korea, (5) Finland, (6) Japan, (7) Canada, (8) Estonia, (9) Belgium, (10) UK/Denmark, (12) Italy, (13) Taiwan, (14) Australia, (15)Norway. This latest edition of the Waseda Ranking surveys the e-Government development of 50 countries altogether. New to the 2011 ranking are 10 countries, which were added to the survey for the first time: Czech Republic, Egypt, Georgia, Iran, Israel, Macau SAR, Pakistan, Portugal, Romania, and Uzbekistan. In order to obtain the latest and most accurate information, along with the assessment of relevant web pages and reports as well as interviews members of the
Institute attended local and international e-Government conferences, conducted meetings with government officials and research institutions in major countries.

The Waseda University Institute of e-Government is also in charge of the Asia Pacific Economic Cooperation (APEC) e-Government Research Center. In coordination with APEC, the Institute has been continuously monitoring and researching on the development of e-Government strategies of APEC member economies since 2004 as part of the activities of the "e-APEC" initiative.

\section{Main Trends of e-Government by Indicators}

Altogether, there are seven main indicators used to carry out the survey. These indicators are: network preparedness, required interface-functioning applications, management optimization, national portal, CIO in government, e-Government promotion and e-participation. These seven indicators comprise 31 dimensions, which are further broken down into sub indicators.

\subsection{Network Preparedness}

Network Preparedness, the basic infrastructural foundation for the implementation of e-government has already been long established in many countries. Internet users indicate Internet access for citizens' results in major opportunities to apply e-Government services. Broadband penetration is considered one of the key market indicators allowing access to the designated online service in high speeds that will stimulate willingness to use such services and development of new services. Mobile phone usage indicates a way of interaction regardless of location. Thus, higher penetration will project likelihood of accessing e-government. The major accessing platform for many e-government 


\begin{tabular}{cll}
\hline No & Final Rankings & Score \\
\hline 1 & Singapore & 92.14 \\
2 & USA & 92.13 \\
3 & Sweden & 88.32 \\
4 & Korea & 87.50 \\
5 & Finland & 86.90 \\
6 & Japan & 86.85 \\
7 & Canada & 85.13 \\
8 & Estonia & 84.10 \\
9 & Belgium & 83.55 \\
10 & UK & 82.40 \\
10 & Denmark & 82.40 \\
12 & Italy & 81.20 \\
13 & Taiwan & 79.31 \\
14 & Australia & 78.50 \\
15 & Norway & 77.61 \\
16 & Spain & 75.30 \\
17 & Germany & 73.15 \\
18 & France & 72.05 \\
19 & Switzerland & 71.88 \\
20 & Netherlands & 70.75 \\
21 & New Zealand & 70.21 \\
22 & Portugal & 69.02 \\
23 & Thailand & 67.67 \\
24 & Malaysia & 67.37 \\
25 & Philippines & 65.10 \\
26 & HongKong SAR & 63.50 \\
27 & Tunisia & 62.10 \\
28 & Mexico & 62.05 \\
29 & China & 60.80 \\
30 & India & 60.15 \\
31 & South Africa & 59.71 \\
32 & Israel & 58.80 \\
33 & Turkey & 57.50 \\
34 & Macau SAR & \\
35 & Russia & 57.10 \\
36 & Indonesia & 56.88 \\
37 & Egypt & 56.13 \\
38 & Vietnam & 55.70 \\
39 & Czech Republic & 51.80 \\
40 & Romania & 49.15 \\
41 & Brazil & 48.80 \\
42 & Brunei & 46.50 \\
43 & Chile & 42.15 \\
44 & Kazakhstan & 38.14 \\
45 & Peru & 35.20 \\
46 & Pakistan & 32.81 \\
47 & Fiji & 30.10 \\
48 & Iran & 26.10 \\
49 & Uzbekistan & 25.11 \\
50 & Georgia & 22.46 \\
\hline & & \\
& &
\end{tabular}

services is personal computers. Hence, being in the information age requires computer literacy.

In first place in this indicator is Sweden, the same place last year, followed by Norway and Netherlands tied for second. Both countries are a step forward compared to last year's rankings. Denmark and Korea tied at fourth. Korea has made rapid progress over the previous year, proving that it has very good strategies to develop the infrastructure. Switzerland and UK in

\begin{tabular}{cl}
\multicolumn{2}{c}{ Network preparedness } \\
\hline No & Network \\
& Preparedness \\
\hline $\mathbf{1}$ & Sweden \\
$\mathbf{2}$ & Norway \\
$\mathbf{2}$ & Netherlands \\
$\mathbf{4}$ & Denmark \\
$\mathbf{4}$ & Korea \\
6 & Switzerland \\
6 & UK \\
8 & Singapore \\
9 & Japan \\
9 & Finland \\
11 & Germany \\
12 & USA \\
\hline
\end{tabular}

the same position, Singapore was ranked first in the total ranking but in this indicator, it only came at 8th.

A few countries in Southeast Asia (Malaysia, Thailand, and Vietnam) have also improved over last year while standing in the near middle of the rankings.

\subsection{Management Optimization}

This indicator reflects the usage of ICT for improving internal processes and measures the government's computerization efforts and the level of ICT integration attainment.

\begin{tabular}{ll} 
Management Optimization \\
\hline Management Op. \\
\hline 1 & France \\
1 & Germany \\
3 & Singapore \\
4 & Estonia \\
5 & New Zealand \\
6 & Denmark \\
6 & Finland \\
6 & Korea \\
9 & Netherlands \\
9 & Norway \\
9 & Portugal \\
9 & USA \\
\hline
\end{tabular}

The government's efforts in these areas are quantified using the Capability Maturity Model to grade each government based on the level of maturity of their ICT integration.

Standardization of service procedures and information system to achieve the internal effectiveness and efficiency of governmental operations can be constrained by different reasons.

The Management Optimization indicator, the grouping of country rankings is becoming obvious as well. At first place in this indicator are two countries: France, Germany followed by Singapore (3rd) and Estonia 
Table 1

Historical trends of ranking for 2005-2011

\begin{tabular}{|c|c|c|c|c|c|c|c|c|c|c|c|c|c|}
\hline & 2005 & & 2006 & & 2007 & & 2008 & & 2009 & & 2010 & & 2011 \\
\hline 1 & USA & 1 & USA & 1 & USA & 1 & USA & 1 & Singapore & 1 & Singapore & 1 & Singapore \\
\hline 2 & Canada & 2 & Canada & 2 & Singapore & 2 & Singapore & 2 & USA & 2 & UK & 2 & USA \\
\hline 3 & Singapore & 3 & Singapore & 3 & Canada & 3 & Canada & 3 & Sweden & 2 & USA & 3 & Sweden \\
\hline 4 & Finland & 4 & Japan & 4 & Japan & 4 & Korea & 4 & UK & 4 & Canada & 4 & Korea \\
\hline 5 & Sweden & 5 & Korea & 4 & Korea & 5 & Japan & 5 & Japan & 5 & Australia & 5 & Finland \\
\hline 6 & Australia & 6 & Germany & 6 & Australia & 6 & $\begin{array}{l}\text { Hong } \\
\text { KongSAR }\end{array}$ & 5 & Korea & 6 & Japan & 6 & Japan \\
\hline 7 & Japan & 7 & Taiwan & 7 & Finland & 7 & Australia & 7 & Canada & 7 & Korea & 7 & Canada \\
\hline 8 & $\begin{array}{l}\text { HongKong } \\
\text { SAR }\end{array}$ & 8 & Australia & 8 & Taiwan & 8 & Finland & 8 & Taiwan & 8 & Germany & 8 & Estonia \\
\hline 9 & Malaysia & 9 & UK & 9 & UK & 9 & Sweden & 9 & Finland & 9 & Sweden & 9 & Belgium \\
\hline 10 & UK & 10 & Finland & 10 & Sweden & 9 & Taiwan & 10 & $\begin{array}{l}\text { Germany } \\
\text { Italy }\end{array}$ & 10 & $\begin{array}{l}\text { Taiwan, } \\
\text { Italy }\end{array}$ & 10 & $\begin{array}{l}\text { UK } \\
\text { Denmark }\end{array}$ \\
\hline
\end{tabular}

(4th). Given that management optimization along with network preparedness constitute foundations for effective implementation of e-Government, it can be quite expected that the countries with mature e-Government have well established interoperability frameworks and administrative systems. While the indicator is still able to separate good management optimization practices as opposed to "best" management optimization practices, the number of countries entering the 'good cluster is expanding. Thus, the indicator requires a further refinement to provide better discrimination among the countries.

\subsection{Required Interface-Functioning Applications}

The availability of user-friendly and secure electronic services is the ultimate goal of e-Government initiatives. The indicators measures 9 core e-services such as e-Tender system, e-Tax systems, e-Voting, e-Payment system, Social Security services (involving payment of pensions, social benefits and insurance), Civil Registration services (securing birth, marriage certificates). In addition to the evaluation criteria mentioned above, the ranking is capturing the presence of Cyber Laws (Cyber Security and e-Commerce Laws) and security system features to protect all transactions/activities across the Internet and among government offices and instrumentalities. The most recent trends show a number of governments in developing countries shifted to user-oriented strategies and maintained one-stopservice portals with plans to gradually expand and enhance its service delivery.

The results of the survey have USA at first place followed by Singapore. Australia and Canada are sharing the third position. In fifth place, three countries are tied: Korea, France, and Japan, which improved its performance since last year. While the very best
Table 2

Indicators and Dimensions

\begin{tabular}{ll}
\hline Indicators & Dimensions \\
\hline 1. Network Preparedness & 1-1 Internet Users \\
& 1-2 Broadband Subscribers \\
& 1-3 Mobile Cellular Subscrib- \\
& ers \\
1-4 PC Users \\
2. Management & 2-1 Optimization Awareness \\
Optimization & 2-2 Integrated Enterprise Ar- \\
& chitecture \\
& 2-3 Administrative and Bud- \\
getary Systems \\
3. Required Interface- & 3-1 Cyber Laws \\
Functioning Applications & 3-2 e-Tender systems \\
& 3-3 e-Tax system \\
& 3-4 e-Payment system \\
& 3-5 e-Voting system \\
& 3-6 Social Security Service \\
3-7 Civil Registration \\
3-8 Consular Services \\
3-9 Labor Related Service \\
3-10 e-Health system \\
4-1 Navigation \\
4-2 Interactivity \\
4-3 Interface \\
4-4 Technical \\
5-1 GCIO Presence \\
5-2 GCIO Mandate \\
5-3 CIO Organizations \\
5-4 CIO Development Progra- \\
ms \\
6-1 Legal Mechanism \\
6-2 Enabling Mechanism \\
6-3 Support Mechanism \\
6-4 Assessment Mechanism \\
7-1 e-Information and Mecha- \\
nisms \\
7-2 Consultation \\
7-3 Decision-Making \\
\\
\end{tabular}

e-Government application functions stand out and are able to differentiate themselves, the rest is making a steady progress and will be soon prepared to challenge the leaders. 


\begin{tabular}{ll} 
Required Interface \\
\hline No & $\begin{array}{l}\text { Required } \\
\text { Interface }\end{array}$ \\
\hline 1 & USA \\
2 & Singapore \\
3 & Australia \\
3 & Canada \\
5 & Korea \\
5 & France \\
5 & Japan \\
8 & Denmark \\
9 & Estonia \\
9 & New Zealand \\
\hline
\end{tabular}

\subsection{National Portal/Home page}

The national portal is the basic interface for stakeholders to access government in an electronic way. The ranking identifies four factors affecting the portal significantly. The four factors are navigation, interactivity, interface, and technical. Eighteen parameters are adopted to evaluate the interface of a national portal. The layout, text, color, and consistency are the main focus in this aspect, as well as the multi-language provision, print and multimedia functions. As for navigation, 14 parameters are employed to test the basic functions of a portal, such site map, search engine, help function, and so on. Interactivity is measured with 15 parameters, which include a real contact information provision, e-mail function provision, SNS (social network service) or online community services, online polls etc. There are 12 parameters adopted for technical indicator to test the innovativeness of the portal.

\begin{tabular}{cl}
\multicolumn{2}{c}{ National portal } \\
\hline No & $\begin{array}{l}\text { National } \\
\text { Portal }\end{array}$ \\
\hline 1 & USA \\
2 & UK \\
3 & Singapore \\
4 & Japan \\
5 & France \\
5 & Sweden \\
7 & Estonia \\
8 & Finland \\
8 & South Arica \\
10 & Canada \\
11 & Germany \\
\hline
\end{tabular}

And yet again the results show the continued dominance of the USA national portal USA.gov, which is No. 1 for this indicator for the 3rd year. The USA portal continues to lead the way in terms of design, navigation, and innovative and extensive use of web 2.0 technology.
Missing few accessibility features and some Web 2.0 tools UK is ranked the second, followed by Singapore at third. Japan placed at fourth, then France, Sweden tied at fifth, while Estonia at seventh, Finland and South Africa placed eighth.

Unavailability of enhanced content, such as multimedia shows does not always indicate a lack of government attention to the functionality of the websites. The portal of Finland is designed so that all information can also be accessed without flash, allowing accessing the portal from a mobile device as it is, without designing a separate mobile version. However, Finland along with other countries has some other opportunities for improving its website. Though they might be rich in online services, they demonstrate extensive opportunities in improving their technical specifications, security, and interaction features among others. It is also common that the quality of national portals in those countries is apparently lagging behind those of other governmental authorities and institutions. For instance, websites of the president, prime minister are demonstrating excellent functionality and innovations unlike the national portals.

\subsection{Government $\mathrm{CIO}$}

$\mathrm{CIO}$ is expected to integrate management strategy with IT investment in order to achieve a balance between the business strategy, organizational reform, and management reform. Thus, the post of Government CIO (Chief Information Officer) is seen by many governments to be one of the key factors in the success of e-Government implementation. In the Waseda survey, the CIO indicator measures firstly for the presence of CIOs in government; secondly, the extent of their mandate; thirdly, existence of organizations which foster CIO development, and finally, special development courses and the degree/quality to which they teach CIO related curricula.

\begin{tabular}{cl}
\hline No & CIO \\
\hline 1 & USA \\
2 & Singapore \\
3 & Korea \\
4 & Canada \\
4 & Japan \\
6 & Thailand \\
7 & Australia \\
8 & Norway \\
8 & UK \\
8 & New Zealand \\
8 & Sweden \\
\hline
\end{tabular}


The results of the 2011 Survey for this indicator show USA ranked first, followed by Singapore at second, Korea third. Canada and Japan are tied at fourth followed by Thailand at sixth, Australia at seventh and Norway, UK, Sweden and New Zealand tied at eighth.

The countries leading in this indicator have established GCIOs (or equivalent titles) responsible for eGovernment implementation. They also have programs for CIO development, bodies for supporting CIO and a framework for CIO functions.

It is worth mentioning that while many governments have established a special position as well as supporting body, that are in charge of decision making and coordination of e-Government development and implementation they are not always referred to as GCIO.

\section{6. e-Government Promotion}

The scope of e-Government promotion includes activities involved in supporting the implementation of e-Government; such as, legal frameworks, promotion activities, organizations/bureaus involved, budgetary distribution system and the existence of third-party committees for over-sight evaluators. The evaluation of e-Government Promotion indicator has been done by using a comprehensive list of evaluation parameters which evaluates a degree of development in each section and a current status of each government's eGovernment promotion development.

\begin{tabular}{ll}
\hline No & $\begin{array}{l}\text { e-Government } \\
\text { promotion }\end{array}$ \\
\hline 1 & Singapore \\
2 & Korea \\
3 & Japan \\
4 & Canada \\
5 & Australia \\
5 & Norway \\
7 & USA \\
7 & Portugal \\
9 & Italy \\
9 & Belgium \\
\hline
\end{tabular}

Singapore has now taken first place for its eGovernment promotional activities, followed closely by Korea. Japan is ranking in third place. Canada is ranked fourth respectfully. Australia and Norway are tied at fifth, followed by USA and Portugal. It can be seen that in spite of availability of quality egovernment, the leading countries still pay a lot of attention to promotional activities in popularizing of the use of e-services and in development of e-Government at local levels.
Much of the efforts of less developed countries are directed at improvement of ICT literacy among their citizens and employees, they are still struggling with the approval of e-Government legislation, assignment of external over-sight evaluation committees and finding proper e-Government funding a strategies.

\section{7. e-Participation}

An e-Participation indicator is used to take into account the "demand" side of e-Government as well as to see to what degree people are using e-government platforms especially in the light of Gov 2.0 mash ups. The Waseda ranking adopts the UN definition and measuring a presence of e-participation through three sub-indicators, i.e. e-information, e-consultation and edecision making that are dissected in many parameters upon which e-participation is measured.

\begin{tabular}{cl}
\multicolumn{2}{c}{ e-Participation } \\
\hline No & e-Participation \\
\hline 1 & Australia \\
1 & Estonia \\
1 & USA \\
4 & Denmark \\
4 & Germany \\
6 & UK \\
7 & Finland \\
7 & Korea \\
7 & Portugal \\
7 & Canada \\
7 & Sweden \\
\hline
\end{tabular}

For this indicator, Australia, Estonia and USA are joint leaders. Denmark and Germany are tied at fourth, followed by the UK. Then there are five countries tied at seventh place; Finland, Korea, Portugal, Canada, and Sweden. Interestingly, the leader of the overall ranking Singapore is sharing the next group with another nine countries (economies): Hong Kong SAR, Netherlands, Chile, Israel, Brazil, Mexico, Malaysia, Japan and Switzerland.

This might suggest that again there is grouping of nations as advanced and e-participation tools become more common.

\section{Trends by grouping in 2011}

This latest edition of the Waseda Ranking surveys the e-Government development of 50 countries (economies) altogether. New to the 2011 ranking are ten countries (economies), This comparison based on 
four groups, group 1 is the upper scoring, group 2 is the middle scoring economies, group 3 is the lower scoring economies, and last one is the new entry group.

\section{Group 1: The upper scoring countries (economies)}

Compared with the previous year, this group in 2011 has some changes. However, Singapore, USA, Sweden and Korea have appeared always in this category of ranking. Estonia having significantly improved its e-government development scores for the first time entered top 10 in 2011 survey. Korea was ranked fourth, followed by Finland as fifth. Explanation for standing that they have achieved very high scores in most of the indicators. Belgium moved significantly, it jumped up to 9 th in the rankings this year because it got high score with many indicators.

\section{Group 2: The middle scoring countries (economy)}

In the middle of table of rankings, Spain upgrades one level and ranked at 16th in the rankings. Compared with previous year, the Southeast Asia countries retain their position in the rankings. Thailand advances by one rank and Malaysia at the same compared last year. In the countries of middle class, both China and Philippines are almost in the same ranking compared last year.

\section{Group 3: The lower scoring countries (economies)}

At the lower rank of the table there is not much change compared last year, is still the old countries such as Chile, Peru, Brunei and Fiji. However, in the rankings this year, in five positions to four new countries, were added to the survey for the first time: Pakistan, Iran, Uzbekistan, and Georgia. These countries receive lower scores on most indicators.

\section{Group 4: The new entry countries (economies)}

The new entry economy, which were added to the survey for the first time in Waseda University World EGovernment 2011 Rankings: Czech Republic, Egypt, Georgia, Iran, Israel, Macau, Pakistan, Portugal, Romania, and Uzbekistan.

Among these countries, the highest ranked is Portugal with 22nd place, it has good current national eGovernment strategies as well as e-services. They received very high scores in the required interface indicator such as e-tender systems, e-payment systems and labor related services as well as e-health system it got high score. E-participation is also advantage point of Portugal. However, CIO indicator is the lowest score for Portugal. Comparison with other countries in the region, Portugal has a very good position in the rankings. Followed by Egypt, which placed 37th for the first time ranked, a feature of the new countries was ranked, they had very low score with CIO indicator, and this indicates that there is little CIOs are in minor positions as well as CIOs have not being considered important to development.

\section{New Trends of e-Government development by the Survey in 2011}

This is the 7th edition of the annual "Waseda World e-Government Ranking" which has been carried out since 2005. Over the past seven years, the Waseda eGovernment research team has surveyed the developments and observed the trends in the e-government arena. Some of the more prominent or interesting trends deal not just with technological developments but also "paradigms" of how ICT is to be viewed within the context of solving problems. The following then are the top trends, which show great promise in affecting or are already impacting e-Government development: for readers who have not accessed survey last year for 2010, the major trends described are listed for reference since these trends continue to extend this year as well.

Government 2.0 - The continued increase in the use of Government 2.0 applications as social media in government sites thereby improving eparticipation and going on Government 3.0-Social media is the fastest growing channel where citizens are engaging with government agencies, and it demands real-time attention. The next frontier in government is thinking about and implementing Web 3.0, with a social twist. The Government 3.0 is about citizen centered innovation (Level 2 participation), the convergence of business applications and social media platforms, the semantic web (self-learning knowledge and technology) and personalization.

Smart-grid and green technology - The growing interest ICT government organizations have for green ICT. A number of governments have responded and have already begun looking at ICT as a tool to address environmental problems, as well as looking at making ICT usage itself more environmentally friendly.

Cloud computing, data center virtualization and shift to all-IP network - Many government ICT managers are showing interest. Cloud computing promises real costs savings and agility to customers. Through cloud computing, e-government can rapidly 
deploy applications where the underlying technology components can expand and contract with the natural ebb and flow of the business life cycle.

Mobile Government - With the implementation of internet into mobile devices, with the combination of these two, the ubiquitous connectivity has become a reality. The advancement of ICT explains why new m-government applications emerge and why government has many opportunities through the wireless channels. M-government with smartphone will join the main stream in the near future

Disaster Reduction \& Business Continuity Planning (BCP) - In the light of terrorism threats, natural disasters, and cyber security threats, Governments have been looking at and reviewing their disaster reduction and business continuity plans.

e-Inclusion - means both inclusive ICT and the use of ICT to achieve wider inclusion objectives. It focuses on participation of all individuals and communities in all aspects of the information society.

Digital Divide - Levels of inequality in access to ICTs remain high still, around twice-average levels of income inequality.

One Stop Service - With the shift to user-oriented strategies to service delivery, many countries are putting their efforts to offer much more diverse, advanced, and comprehensive electronic services through one-stop portals.

Coordination and collaboration between central and local governments is nowadays a key factor for delivery of public services.

Citizen centric e-Participation - This is about reconnecting ordinary people with politics and policymaking and making the decision-making processes easier to understand and follow through the use of new Information and Communication Technologies.

Trends observed this year is the special attention governments gave to Green ICT / Environmental ICT issues. Other trends observed are the use of Government 2.0 mash ups using Web 2.0 technology. In particular, there is an increase in real time SNS applications such as Twitter in government sites. This leads to another trend which is the increase in the quality and depth of eparticipation between users and governments. Stronger linkages between local and central government are also implemented. Cloud computing is another topic of great interest to many governments with a view towards reducing operating costs as well as carbon footprints. To summarize the top 5 most interesting items observed are as follows:

\section{Top 11 priority areas for attention to the activities of e-government in 201}

(1) Popularity of Mobile government

(2) Contributing to Green government

(3) Transformation of Open government

(4) Provision of One Stop Service

(5) Usage of Broadband network for all

(6) Citizen inclusion by e-participation for achieving the goals for the demand side of eGovernment

(7) Techno innovation such as Cloud computing

(8) Accessibility to the vulnerable groups including the ageing people

(9) Government 2.0 as emerging social media

(10) Reassessing indicators/benchmarks with reliable e-Government measurement

(11) Strengthening Capacity building -training program of ICT Human resource development for CIO (Chief Information Officer)

As for priority (10) in the above lists, we have started to discuss both the evaluation system and harmonization scheme of indicators with OECD, United Nations DESA, World Economic Forum GAC, etc. Particularly Waseda staff had the meetings with the officers responsible for e-government at OECD for four times in 2010 .

\section{New policy agendas for 2011}

Waseda University is emphasizing specially the above (8) and (11) as the emerging critical agendas

As for (8), the role of e-Government on accessibility and usability to the vulnerable groups such as ageing people, handicapped persons, foreign residents and etc, will become the important global issue. We have started the research project on SILVER INNOVATION and ECONOMY [ICT applications for ageing society] with OECD. The research work will be based on a comparative analysis conducted at international level in order to guarantee results with a higher level of robustness and generalizability. The project will include accumulation of relevant data, evaluation and comparative analysis of experiences as the best practices , and implementation of ICT for ageing society in all concerned countries faced with the similar problems of drastic increase of ageing population.

Another issue is [CIO] at (11) which is listed as one of seven indicators for the ranking measurement. CIO is ICT leader in both public and private sectors with inter- 
active cooperation in Innovation as well as information system. An important objective of e-Gov is to make the government more transparent for e-Democracy and increase the quality of life with ICT. In the near future, the majority of both central and local governments are expected to consolidate management of e-Government programs under CIOs at all levels of government sectors. This will be due to the increasing complexity of e-government programs and the pressing need to coordinate whole of e-government applications to meet the needs of citizens and business. There will also be a corresponding demand in establishing training programs to systematically develop CIOs as some leading countries already implement. On this regard, International Academy of CIO (IAC) was established in 2004 with the Secretariat in Bangkok. This global organization is playing an important role of the CIO training and education programs, which Waseda University is a Chair institute of IAC.

Finally, for your reference, IOS Press in Amsterdam is publisher of The Global e-Governance Book Series www.iospress.nl The volume The Innovative CIO and e-Participation in e-Government Initiatives was edited by Prof. Toshio Obi in 2010, which contains all country research reports for the targeted e-governments rankings for 2010. Also, the Journal of Global eGovernance is published quarterly by IOS Press, and has made the special editions of Waseda University e-Government ranking for 2010 and 2011 respectively. 